\title{
Combination Therapy of a Host Defense-Like Lytic Peptide and Continuous Low-Dose Doxorubicin Inhibits Tumor Growth in a Syngeneic Immunocompetent Murine Fibrosarcoma (BFS-1) Model
}

Jan Philip Suppelna ( $\nabla$ philip.suppelna@web.de)

Kliniken Essen-Mitte Evangelische Huyssens-Stiftung/Knappschaft GmbH

Kamran Harati

Sektion Plastische Chirurgie, Westfalische Wilhelms-Universitat Munster

Andrea Rittig

Arbeitsgruppe Experimentelle Plastische Chirurgie, Berufsgenossenschaftliches Universitatsklinikum Bergmannsheil

Ingo Stricker

Berufsgenossenschaftliches Universitatsklinikum Bergmannsheil

Markus Lehnhardt

Berufsgenossenschaftliches Universitatsklinikum Bergmannsheil

Yechiel Shai

Israel Department of Biomolecular Science

Maximilian Kückelhaus

Sektion Plastische Chirurgie, Westfalische Wilhelms-Universitat Munster

Tobias Hirsch

Sektion Plastische Chirurgie, Westfalische Wilhelms-Universitat Munster

Frank Jacobsen

Arbeitsgruppe Experimentelle Plastische Chirurgie, Berufsgenossenschaftliches Universitatsklinikum Bergmannsheil

Research article

Keywords: Sarcoma, Metastases, Lung, Tumor lytic peptide, Cancer, Mouse model

Posted Date: March 4th, 2020

DOI: https://doi.org/10.21203/rs.3.rs-15914/v1 
License: (c) (i) This work is licensed under a Creative Commons Attribution 4.0 International License. Read Full License 


\section{Abstract}

Background: The concept of a multimodality therapy in the treatment of soft tissue sarcomas (STS) has been discussed with controversy. Surgical resection with clear margins and radiation therapy remain gold standard in STS therapy. It is still questionable whether a systemic therapy with chemotherapeutics has a positive impact on the overall survival rate especially in early stages of disease, because the therapeutic effect in the treatment of STS is limited by its toxicities and its low responding rates. Treatment options are rare. As a result the search for combination therapies by using low dose approaches is of high importance. Recent studies showed the therapeutic efficiency of a designer host defense-like lytic $D, L-$ amino acid peptide [D]-K $3 \mathrm{H} 3 \mathrm{~L} 9$. Therefore we tested a combination of this peptide with Doxorubicin on two different sarcoma cell lines in vitro and also in a syngeneic immunocompetent murine fibrosarcoma mouse model.

Methods: In vitro the human synovial sarcoma cell line SW 982 and the murine fibrosarcoma cell line BFS-1 were exposed to the oncolytic peptide [D]-K $3 \mathrm{H} 3 \mathrm{~L} 9$, to the Anthracycline Doxorubicin and to both agents simultaneously. In vivo the murine fibrosarcoma cell line BFS-1 was injected subcutaneously into the syngeneic mice. When the tumors engrafted the oncolytic designer peptide [D]-K $3 \mathrm{H} 3 \mathrm{~L} 9$, Doxorubicin or a combination of both was administered thrice a week for a three weeks' follow-up.

Results: The combination treatment approach using an oncolytic designer host defense peptide and Doxorubicin inhibited the in vitro sarcoma cell proliferation significantly. The single therapies, either with local intratumoral application of [D]-K 3 H 3 L 9 or with intraperitoneal application of Doxorubicin in the syngeneic mouse model, inhibited at least the tumor progression. The combination of both substances revealed a significant inhibition of tumor growth and weight.

Conclusion: The in vivo low dose combination schedule inhibited the tumor growth significantly. Histological analyses of the tumor sections revealed an antiproliferative and antiangiogenic effect. So, these results demonstrate the effectiveness of combined low-dose application forms with designer host defense-like lytic peptides and chemotherapeutics.

\section{Background}

Soft Tissue Sarcomas (STS) are a very rare heterogenous group of malignant neoplasias, representing about $1 \%$ of all cancer cases in adults whereas in children sarcomas account for approximately $7 \%$ of all pediatric malignancies (1-3). They have an annual incidence of two to three cases per 100.000 (4). Soft tissue sarcomas arise in tissues of mesenchymal origin such as fat, muscles, nerves, tendons and blood and lymph vessels -the soft tissues that connect, support, and surround other parts of the body (5, 6). The five-year survival rate is approximately $50 \%$ (7) whereas up to $60 \%$ of high grade STS spread to distant organs, most commonly to the lungs (8). Large high-grade sarcomas and a late diagnosis have a poor cure rate with surgery alone (9). Surgical resection has the biggest part in the therapy of soft tissue sarcomas. The aim for an effective treatment in extremity tumors is to get a wide resection margin while 
sparing the function which is the main prognostic factor for local and systemic tumor control (10-12). But effective treatment usually requires a radiotherapy to improve the local control rates and to minimize the risk of recurrence in intermediate and high grade STS (13-15). Even in early stages of disease, the combination of surgical procedures and preoperative/ postoperative radiation therapy (preRX/ PORT) is preferred to radical surgical procedures that were common the past, e.g. amputation $(14,16)$.

In locally advanced or metastatic cases, systemic therapy has an important role in the multidisciplinary management of sarcomas in the setting of controlled clinical studies (17). The problem is STS's low response rate to most of the single or multiple chemotherapeutic regimens (18). Only Doxorubicin, Epirubicin and Ifosfamide had response rates of $18 \%-29 \%$ in the first line treatment with a single agent activity of more than $15 \%(19,20)$. Whereas the response rate of anthracyclines in combination with ifosfamide was $40 \%$ - $50 \%$ but was also associated with severe short- and long-term toxicities including bone marrow suppression and cardiomyopathy (21). Furthermore, there is no study existing in the past, which has clearly proved the relapse-free or the overall-survival benefit after chemotherapeutic treatment.

Looking for novel therapeutic alternatives, recent studies showed the improved oncolytic effect of synthesized D-amino acid peptides (22-24). They have their origin as Host defense peptides (HDPs) in the innate immune system, where they are expressed in a great variety of organisms (27-29). HDPs were already put in focus as oncolytic agents to potentially exceed the limits of current agents $(25,26)$. At first they were seen as primarily antimicrobial active substances, but HDPs proved to have significant cytotoxic effects against malignant cells including bladder, breast and lung cancers as well as lymphomas, leukemia and sarcomas $(25,26,30-34)$. This oncolytic effect is caused via a membrane disrupting mechanism due to their molecular characteristics. HDPs are very short (10-40 amino acids) amphipathic and cationic proteins. Their positive charge leads to a higher affinity to the negatively charged membrane of tumor than to zwitterionic membranes of normal mammalian cells, based on the electrostatic interaction $(26,31,35-37)$. The limiting factor for their oncolytic potential in in vivo studies is their inactivation through enzymatic degradation or adhesion to serum components. In this context, research has focused on modifying the molecules' structure to become first active in acidic tumor environments and therefore pass systemic degradation resulting in cationic peptides containing synthetic D-amino acids. This defines the difference between naturally occurring L-amino peptides to artificially synthesized D-amino peptides, resulting in higher adhesion to negatively charged membranes, the decrease in enzymatic degradation and the reduced negative side effects, as hemolysis, e.g. $(38,39)$. The host defense-like lytic peptide [D]- $\mathrm{K}_{3} \mathrm{H}_{3} \mathrm{~L}_{9}$ used in this study consists of the $\mathrm{D}$ - and L-amino acids lysine, histidine and leucine. The activation of HDP in acidic environment in solid tumors is based on the changed metabolic and nutritional environment. The peptide becomes cationic by protonating histidine (pKa, 6.1) below pH 7.0 which leads to a selectivity against malignant tissue (22). The antiproliferative and antiangiogenic activity of the $[D]-\mathrm{K}_{3} \mathrm{H}_{3} \mathrm{~L}_{9}$ peptide could already be seen in preovious studies in a prostate cancer xenograft model and furthermore in suppression of soft tissue sarcoma in vitro and in vivo $(22,37,40)$. 
The aim of this study was to establish a syngeneic immunocompetent murine fibrosarcoma (BFS-1) model that would allow a study of host defense-like lytic peptide [D]- $\mathrm{K}_{3} \mathrm{H}_{3} \mathrm{~L}_{9}$ and Doxorubicin combination therapy, comparing the efficiency in vivo with the in vitro results.

\section{Methods}

\subsection{Cell culture}

The SW982 human synovial sarcoma cell line (Cell Line Service (CLS), Eppelheim, Germany), proved via nonaplex Polymerase Chain Reaction (PCR) in July, 2015 was cultivated in Dulbecco's Modified Eagle's Medium (DMEM) with 10 \% Fetal Calf Serum (FCS) (Thermo Fisher Scientific Inc., Waltham, MA, USA) and $1 \%$ penicillin/streptomycin (PAA laboratories, Pasching, Austria). The murine fibrosarcoma cell line BFS-1wt (generously provided by Prof. T. Hehlgans, Department of Immunology, Regensburg, Germany) was hold in RPMI 1640 culture medium with $10 \% \mathrm{FCS}$ and antibiotics. Both cell lines were kept in a $\mathrm{CO}_{2}$ (5\%) $37^{\circ} \mathrm{C}$ incubator. The experiment started when the cells were grown confluent, medium changed twice a week.

\subsection{Peptide and chemotherapeutics}

The host defense-like lytic peptide [D]-K $\mathrm{K}_{3} \mathrm{H}_{3} \mathrm{~L}_{9}$, a short 15-mer D,L-amino acid peptide (LHLLHKLLKHLLKLL-NH2, D-amino acids underlined), was obtained by solid-phase synthesis and purified by RP-HPLC (NeoMPS S. A., Strasbourg, France) resulting in a concentration of $99.4 \%$. (The peptide's sequence was generously provided by Prof. Yechiel Shai, Department of Biological Chemistry, The Weizmann Institute of Science, Rehovot, Israel.). Doxorubicin was used as chemotherapeutic agent (Pharmacia Bergmannsheil).

\subsection{Animals}

All guidelines for the care and use of animals, stated by the Ministry for Environment, Agriculture, Conservation and Consumer Protection of the State of North Rhine-Westphalia, were followed. Immunocompetent C57/BL6 mice (Harlan Winkelmann GmbH, Borchen, Germany) (weighing 20-25 g, age 5 - 6 weeks old) were used throughout this study. Their racks were ventilated and pathogen free. They were held in equinox conditions ( $12 \mathrm{~h}$ light $/ 12 \mathrm{~h}$ dark) with control of humidity and temperature $\left(23+/-2^{\circ} \mathrm{C}\right)$. Sterile requirements were maintained throughout all surgical procedures.

\subsection{Cell proliferation}

Bromo Deoxyuridine (BrdU) cell proliferation enzyme-linked immunosorbent assay (ELISA) kit (Roche Diagnostics $\mathrm{GmbH}$, Mannheim, Germany) was used for measurement of cell proliferation in accordance to the manufacturer's instructions. After seeding the cells in $96-w e l l$ plates ( $3 \times 10^{4}$ cells/well), they grew for 24 hours. Followed by an 24-hour incubation with fresh FCS-free medium containing either the host defense-like lytic peptide [D]- $\mathrm{K}_{3} \mathrm{H}_{3} \mathrm{~L}_{9}$ or Doxorubicin or both agents and a 22-hour incubation after adding 
BrdU labeling solution. BrdU, a pyrimidine analogue, was incorporated into the DNA during cell proliferation and the rate of proliferation could be measured by the light emission detected via an Orion microplate luminometer (Berthold Detection Systems, Pforzheim, Germany). LC50 values for each medium were evaluated. Additionally, cell proliferation was measured using the concentration of the peptide and the chemotherapeutic which inhibited 15 - $30 \%$ of cell proliferation alone. The same concentration of each agent was used measuring the inhibition of cell proliferation with both substances combined and therefore the proliferation was measured in triplicate. The results show the cell viability in percentage compared to the negative control.

\subsection{Solid tumor model}

Murine fibrosarcoma BSF-1 cells in Matrigel (BD Biosciences, San Jose, CA, USA) were injected subcutaneously ( $1 \times 10^{6}$ cells) into the animal's flank using a laminar airflow cabinet. The mice weights were measured and the tumor volume was calculated with the formula of length $\mathrm{x}$ width $\mathrm{x}$ depth $\mathrm{x} 0.5$ in $\mathrm{mm}^{3}$ every second day. When the averaged volume of $130 \mathrm{~mm}^{3}$ (BFS-1) was reached, the animals were randomly grouped following the rules of a randomized control trial. The different groups of mice were treated either with the $[D]-K_{3} H_{3} L_{9}$ peptide $(n=5)$, with Doxorubicin $(n=5)$, with both agents simultaneously $(n=5)$ or with Phosphate buffered saline (PBS) $(\mathrm{pH} 7.0-7.5)$ as a control $(n=5)$ for three weeks from day 0 to day 19. A two-days-follow-up continued to day 21. [D]- $\mathrm{K}_{3} \mathrm{H}_{3} \mathrm{~L}_{9}$ was injected intratumorally thrice a week (single dose $5 \mathrm{mg} / \mathrm{kg} \mathrm{n}=5$ ) and Doxorubicin was injected intraperitoneally twice a week (single dose $1.2 \mathrm{mg} / \mathrm{kg}, \mathrm{n}=5$ ). The experiment was terminated early when a tumor length of over $20 \mathrm{~mm}$ was reached and the animals were euthanized by an overdose of isoflurane followed by cervical dislocation. The tumors were collected and analyzed. The evaluation of the data was based on a Kaplan-Meier graph.

\subsection{Histologic and immunofluorescent staining}

A fixation of the excised tumors in $5 \%$ buffered formaldehyde was followed by a haematoxylin and eosin (H\&E) staining of the paraffin-embedded $23 \mu \mathrm{m}$ sections. The slides of treated tumors were microscopically examined (Zeiss Axioskop 2 Plus microscope) and photographed (AxioCam-HRc). For immunohistochemical examination slides needed to be deparaffinized and rehydrated. Citrate-mediated high temperature antigen retrieval (Vector Laboratories, Burlingame, CA, USA) and incubation with blocking buffers were performed to avoid nonspecific binding of antibodies. To examine the vascularization an incubation with monoclonal anti-human $\mathrm{Ki}-67$ antibody followed (Acris Antibodies $\mathrm{GmbH}$, Herford, Germany) which are specific to proliferating cells and CD31 antibody, known as the platelet endothelial cell adhesion molecule (PECAM-1).

\subsection{Statistics}

Data are reported as mean \pm standard error of the mean (SEM) and all statistical analyses were performed with GraphPad Prism 6.0.1. Moreover, data were analyzed with student t-test or ANOVA if more 
than two groups were compared. Differences were considered as statistically significant with a p-value $<0.05$.

\section{Results}

Cell proliferation was determined after monotherapy with [D]- $\mathrm{K}_{3} \mathrm{H}_{3} \mathrm{~L}_{9}$ or Doxorubicin and comparison to the combination treatment ([D]- $\mathrm{K}_{3} \mathrm{H}_{3} \mathrm{~L}_{9}+$ Doxorubicin (DXR)). The human synovial sarcoma (SW982) and the murine Fibrosarcoma (BFS-1) cell line were simultaneously treated for 24 hours (Figure 1). Afterwards, the examination of the cell proliferation was detected using a BrdU detection system and normalized to carrier control. While single agents provoked a $15-30 \%$ inhibition of proliferation, we examined a possible synergistic effect of the combined use ( $>50 \%$ reduction).

\section{1 Inhibition of solid soft tissue sarcoma growth by intratumoral administration of [D]- $K_{3} \mathrm{H}_{3} \mathrm{~L}_{9}$ and} Doxorubicin in an immunocompetent mouse model

Cells were implanted subcutaneously into the left flank of the immunocompetent C57BL/6 (BFS-1) mice. The oncolytic activity of $[D]-\mathrm{K}_{3} \mathrm{H}_{3} \mathrm{~L}_{9}$ was evaluated after reaching the defined tumor volume of approximately $130 \mathrm{~mm}^{3}$ (Figure 2). The injection of the peptide was adminstered intratumorally at a dose of $5 \mathrm{mg} / \mathrm{kg}$, Doxorubicin was injected intraperitoneally at a dose of $1.2 \mathrm{mg} / \mathrm{kg}$. As expected, there was no significant inhibition of the tumor volume after therapy with both agents in such low dose approaches. During the three weeks of therapy the subcutaneous tumors of the control group showed an exponential growth with a final mean tumor volume of $2157 \mathrm{~mm}^{3}$. In the single-agent therapy they grew to a final mean tumor volume of $1701 \mathrm{~mm}^{3}$ (21\% reduction) under the treatment with Doxorubicin and of $1447 \mathrm{~mm}^{3}$ (33\% reduction) under the [D]- $\mathrm{K}_{3} \mathrm{H}_{3} \mathrm{~L}_{9}$ treatment. The administration of [D] $-\mathrm{K}_{3} \mathrm{H}_{3} \mathrm{~L}_{9}$ and Doxorubicin at the same time led to a significant $(p<0.05)$ reduction of the tumor volume with $49 \%$ and a final volume of $1099 \mathrm{~mm}^{3}$.

These findings were reflected by a significant reduction $(p<0.05)$ of tumor weight of the dissected primary tumors under combined treatment compared to the carrier control group (Figure 2).

[D] $-\mathrm{K}_{3} \mathrm{H}_{3} \mathrm{~L}_{9}+$ Doxorubicin treated mice signed for a significant reduced average tumor weight of $1.56 \mathrm{~g}$ which was about $38.58 \%(\mathrm{p}<0.05)$ lower than the weight in the control group $(2.54 \mathrm{~g})$. For the single agents neither Doxorubicin (mean weight $1.88 \mathrm{~g}, 26 \%$ reduction) nor [D] $-\mathrm{K}_{3} \mathrm{H}_{3} \mathrm{~L}_{9}$ (mean weight $2.12 \mathrm{~g}$, $16.5 \%$ reduction) lead to significant tumor weight reduction. The tumor weight of the $[D]-\mathrm{K}_{3} \mathrm{H}_{3} \mathrm{~L}_{9}$ treated mice was 11.32 \% higher in mean compared to the Doxorubicin group (Figure 2). There were no acute toxicities or adverse events in the therapy groups, all mice could be included into the statistical analyses (5/5 mice in each group).

4.2 Immunostaining with $C D 31$ antibody revealed a highly significant reduction of tumors' vascularization treated with $[D]-K_{3} H_{3} L_{9}$ and Doxorubicin $(p<0.01)$ 
Additionally, a strong antiangiogenic effect of Doxorubicin in addition to the peptide was determined using a CD31 antibody (Figure 4). The immunohistochemical staining using anti-mouse CD31 antibody shows a significant reduction in vessel density within the combined treated tumors compared to the carrier control (PBS). The angiogenesis was quantified by high power field counting. Even in the mono therapy groups there was a significant effect on the tumors' vascularization $(p<0.05)$. In comparison to the control group with 6.96 vessels/High-power field (HPF), vessel density was reduced to 4.8 vessels/HPF (31.03\% reduction) for the peptide group and down to 4.0 vessels/HPF in the Doxorubicin group $(42.53 \%)$. The results were highly significant $(p<0.01)$ for the combined treated group with a vessel density of 2.46 vessels/HPF representing a $64.66 \%$ reduction compared to the carrier control group (Figure 3).

\subsection{Combination therapy with [D]- $K_{3} H_{3} L_{9}$ and Doxorubicin induces necrosis and non-vital areas}

H\&E staining of representative tumor sections of the murine BFS-1 fibrosarcoma were analyzed. In the tumor tissue of the carrier control group a large number of dense, highly proliferative cancer cells was observed. The decrease in tumor staining, a poor nuclear-to-cytoplasmic ratio, and the loss of architecture in the combined treated mice indicate a massive tumor cell death. Even in H\&E stained sections we observed necrotic areas after combination therapy. These necrotic areas were especially found in injection zones, which indicates the direct cytotoxic effect of the oncolytic peptide (Figure 4, upper line). The CD31 immunostaining (Figure 4, middle line) shows some isolated endothelia (brown, red arrows) but no capillary network, which indicates the antiangiogenic efficiency of both substances given simultaneously. The mono therapy with [D] $-\mathrm{K}_{3} \mathrm{H}_{3} \mathrm{~L}_{9}$ peptide alone could neither disturb neoangiogenesis nor even destroy existing capillary networks.

Immunohistochemical staining underlined this effect and showed an overall reduction of 4',6-diamidino2-phenylindole (DAPI) positive cell nuclei (Figure 4, lower line, blue) and a reduction of proliferating Ki-67 positive cells (Figure 4, lower line, green). Furthermore, immunohistological staining suggests that this general decrease in cell count (blue nuclei) and the reduction of proliferating cells (green) was also observed in vital, non-necrotic areas (Figure 5).

\section{Discussion}

This study examined the potential role for a designer HDP [D]- $\mathrm{K}_{3} \mathrm{H}_{3} \mathrm{~L}_{9}$ as a novel oncolytic agent against sarcoma cells, the oncolytic efficiency of a systemic low-dose Doxorubicin schedule and the combination regimen of both agents applicated simultaneously. The peptide itself has emerged due to its potent and possibly tumor selective antiproliferative effects in the past. Several studies show that even the single application form of HDPs elicits potent local growth inhibitory effects in vitro, in in vivo xenograft models of human STS and in in vivo immunocompetent models vivo $(22,37,40)$. Considering that diverse studies examined the oncolytic efficacy of a mono Doxorubicin sarcoma therapy, no significant and satisfying effects could be observed $(41,42)$. Chemotherapeutics' limited clinical effect and their 
toxicities by using as single anti-sarcoma agents calls for the identification of more effective combinational therapeutic approaches.

The molecular mechanisms resulting in combined HDPs' and DXR's antiproliferative and antiangiogenic effects are not well defined.

The highly significant inhibition of sarcoma cell proliferation measured in a BrdU might result as the increased DXR influx into the cells and accumulation inside the cells due to the membrane disrupting effects of the HDP. Tumor growth inhibitory effects in this fibrosarcoma mouse model after combinational use of [D]- $\mathrm{K}_{3} \mathrm{H}_{3} \mathrm{~L}_{9}$ and Doxorubicin is attributable to the addition of the antiproliferative and antiangiogenic effects of both agents, which can be additionally observed in immunohistochemical examinations of solid tumors. The antiproliferative effect of the HDP is based on the increasing development of necrosis and apoptosis of the peptide and DXR, which both act proapoptotic. Several studies showed the activation of the caspases-cascade for HDPs and Doxorubicin, while Doxorubicin especially affects the bcl 2 /bax pathway $(43,44)$. In addition to the antiproliferative effects induced by [D]- $\mathrm{K}_{3} \mathrm{H}_{3} \mathrm{~L}_{9}$ DXR combination, we identified a significant reduction in the number of sarcoma associated blood vessels in response to this therapy. STS are highly dependent on their blood supply for tumor progression and particularly for metastases. Therefore, antiangiogenic drug regimens against STS like Doxorubicin are further major promising approaches (45). However, DXR's clinical value in STS treatment is limited, not least because as a DNA-alkylating drug, its efficacy is dependent on the intracellular concentration. Multidrug-resistance transporting proteins like MDR 1, belonging to the ATPbindingcassette proteins, are further minimizing chemotherapeutic effects by active efflux mechanisms. DXR is one of those drugs which are strongly influenced by these efflux procedures (4648). Whereas the HDP's efficiency seems to be independent by those drug resistances, as a study of HeldKutznetsov et al. showed (49). As we already learned, HDPs kill cancer cells via two suggested mechanisms including a disruption of the plasma membrane via micellization or pore formation that induces necrosis and via a lysis of the mitochondrial membrane leading to apoptosis. To what extent this membrane damaging effect of HDPs affects the Multi Drug Resistance - proteins (MDR-proteins) and prevents the active efflux of chemotherapeutics has not been examined yet. Further studies might also focus on different application regimens. This study examined the HDP related oncolytic potential via local injection of the agent. To find new therapeutic approaches to fight against metastases, the precondition would be further a systemic therapy. Next step might be a mouse model via systemic combination of peptide and chemotherapeutic agents. Here the major issue should be the systemic application of HDPs and the observation of negative side effects, especially in combination with other drugs, like Doxorubicin.

\section{Conclusions}

Oncolytic designer peptides such as $[\mathrm{D}]-\mathrm{K}_{3} \mathrm{H}_{3} \mathrm{~L}_{9}$ seem to introduce a new era of sarcoma therapy. Their strong membranolytic effect will make it difficult for malignant cells to develop new resistance mechanisms. This study not only confirmed what several former reports indicated for the single agent 
therapy with HDPs, but also showed the potential of the oncolytic effect in a combination with chemotherapeutics. It showed that Doxorubicin could reach synergistic effects with HDPs, while having less toxicities being used in a low dose approach. Chemotherapeutics' limited clinical effect and their toxicities by using it as single anti-sarcoma agents call for the identification of more combinatorial therapeutic approaches of designer HDPs with low-dose chemotherapy. This suggests that designer HDPs may play a future role in the sarcoma therapy.

\section{List Of Abbreviations}

STSsoft tissue sarcomas

HDPhost defense peptide

CLSCell Line Service

PCRPolymerase Chain Reaction

DMEMDulbecco's Modified Eagle's Medium

FCSFetal Calf Serum

BrdUBromo Deoxyuridine

ELISAenzyme-linked immunosorbent assay

PBSphosphate buffered saline

H\&Ehaematoxylin and eosin

PECAM-1platelet endothelial cell adhesion molecule 1

SEMstandard error of the mean

DXRDoxorubicin

HPFHigh-power field (HPF)

DAPI4',6-diamidino-2-phenylindole

MDR-ProteinMulti Drug Resistance - Protein

\section{Declarations}

Ethics approval and consent to participate 
This study was approved by the Ministry for Environment, Agriculture, Conservation and Consumer Protection of the State of North Rhine-Westphalia (reference number: 84-02.04.2014.A236). All applicable guidelines for the care and use of animals were followed.

Consent for publication

Not applicable

Availability of data and material

All data generated or analysed during this study are included in this published article.

Competing interests

The authors declare that they have no competing interests.

\section{Funding}

This study was funded by the medical faculty of the Ruhr University Bochum (FoRUM; F862-15). The funders had no role in study design, collection, analysis and interpretation of data, decision to publish, or writing of the manuscript.

\section{Authors' contributions}

J. P. S. developed the idea of the experiment, performed it and analyzed the data. F. J., T. H. and M. L. supervised the project. J. P. S. and A. R. did the laboratory work. Y. S. provided the amino acid sequence for the development of the oncolytic host defence peptide. I. S. was responsible for the histological preparation of the samples. J. P. S. wrote the manuscript in consultation with F. J., T. H., K. H. und M. K.. All authors discussed the results and contributed to the final manuscript.

Acknowledgements:

We thank Stephanie Abraham for excellent technical assistance.

\section{References}

1.Burningham Z, Hashibe M, Spector L and Schiffman JD: The epidemiology of sarcoma. Clin Sarcoma Res 2: 14, 2012.

2.Karakousis CP and Perez RP: Soft tissue sarcomas in adults. CA Cancer J Clin 44: 200-210, 1994.

3.Koscielniak E, Morgan $\mathrm{M}$ and Treuner $\mathrm{J}$ : Soft tissue sarcoma in children: prognosis and management. Paediatr Drugs 4: 21-28, 2002. 
4.Jane MJ and Hughes PJ: Disease incidence and results of extremity lesion treatment: mersey region soft tissue sarcomas (1975-1985). Sarcoma 2: 89-96, 1998.

5.Nielsen TO, West RB, Linn SC, et al: Molecular characterisation of soft tissue tumours: a gene expression study. Lancet 359: 1301-1307, 2002.

6.Skubitz KM and D’Adamo DR: Sarcoma. Mayo Clin Proc 82: 1409-1432, 2007.

7.Eilber FC, Eilber FR, Eckardt J, et al: The impact of chemotherapy on the survival of patients with highgrade primary extremity liposarcoma. Ann Surg 240: 686-695; discussion 695-687, 2004.

8.Chao C, McMasters KM and Edwards MJ: Advances in the treatment of soft-tissue sarcomas. J Ky Med Assoc 100: 10-16, 2002.

9.Billingsley KG, Burt ME, Jara E, et al: Pulmonary metastases from soft tissue sarcoma: analysis of patterns of diseases and postmetastasis survival. Ann Surg 229: 602-610; discussion 610-602, 1999.

10.Baroudi MR, Ferguson PC, Wunder JS, et al: Forearm soft tissue sarcoma: tumors characteristics and oncologic outcomes following limb salvage surgery. J Surg Oncol 110: 676-681, 2014.

11.Lehnhardt M, Hirche C, Daigeler A, et al: [Soft tissue sarcoma of the upper extremities. Analysis of factors relevant for prognosis in 160 patients]. Chirurg 83: 143-152, 2012.

12.Muramatsu K, Ihara K, Doi K, Hashimoto T and Taguchi T: Sarcoma in the forearm and hand: clinical outcomes and microsurgical reconstruction for limb salvage. Ann Plast Surg 62: 28-33, 2009.

13.Suit HD, Mankin HJ, Wood WC and Proppe KH: Preoperative, intraoperative, and postoperative radiation in the treatment of primary soft tissue sarcoma. Cancer 55: 2659-2667, 1985.

14.Yang JC, Chang AE, Baker AR, et al: Randomized prospective study of the benefit of adjuvant radiation therapy in the treatment of soft tissue sarcomas of the extremity. J Clin Oncol 16: 197-203, 1998.

15.Zagars GK, Ballo MT, Pisters PW, et al: Prognostic factors for patients with localized soft-tissue sarcoma treated with conservation surgery and radiation therapy: an analysis of 1225 patients. Cancer 97: 2530-2543, 2003.

16.Williard WC, Hajdu SI, Casper ES and Brennan MF: Comparison of amputation with limb-sparing operations for adult soft tissue sarcoma of the extremity. Ann Surg 215: 269-275, 1992.

17.Cormier JN and Pollock RE: Soft tissue sarcomas. CA Cancer J Clin 54: 94-109, 2004.

18.Cormier JN, Huang X, Xing Y, et al: Cohort analysis of patients with localized, high-risk, extremity soft tissue sarcoma treated at two cancer centers: chemotherapy-associated outcomes. J Clin Oncol 22: 4567-4574, 2004. 
19.Frustaci S, De Paoli A, Bidoli E, et al: Ifosfamide in the adjuvant therapy of soft tissue sarcomas. Oncology 65 Suppl 2: 80-84, 2003.

20.Frustaci S, Foladore S, Buonadonna A, et al: Epirubicin and ifosfamide in advanced soft tissue sarcomas. Ann Oncol 4: 669-672, 1993.

21.Frustaci S, Gherlinzoni F, De Paoli A, et al: Adjuvant chemotherapy for adult soft tissue sarcomas of the extremities and girdles: results of the Italian randomized cooperative trial. J Clin Oncol 19: 12381247, 2001.

22.Makovitzki A, Fink A and Shai Y: Suppression of human solid tumor growth in mice by intratumor and systemic inoculation of histidine-rich and pH-dependent host defense-like lytic peptides. Cancer Res 69: 3458-3463, 2009.

23.Oren $\mathrm{Z}$ and Shai Y: Selective lysis of bacteria but not mammalian cells by diastereomers of melittin: structure-function study. Biochemistry 36: 1826-1835, 1997.

24.Papo N, Braunstein A, Eshhar Z and Shai Y: Suppression of human prostate tumor growth in mice by a cytolytic D-, L-amino Acid Peptide: membrane lysis, increased necrosis, and inhibition of prostate-specific antigen secretion. Cancer Res 64: 5779-5786, 2004.

25.Papo $\mathrm{N}$ and Shai Y: Host defense peptides as new weapons in cancer treatment. Cell Mol Life Sci 62: 784-790, 2005.

26.Steinstraesser L, Kraneburg UM, Hirsch T, et al: Host defense peptides as effector molecules of the innate immune response: a sledgehammer for drug resistance? Int J Mol Sci 10: 3951-3970, 2009.

27. Hancock RE and Scott MG: The role of antimicrobial peptides in animal defenses. Proc Natl Acad Sci US A 97: 8856-8861, 2000.

28.Reddy KV, Yedery RD and Aranha C: Antimicrobial peptides: premises and promises. Int $\mathrm{J}$ Antimicrob Agents 24: 536-547, 2004.

29.Shai Y, Makovitzky A and Avrahami D: Host defense peptides and lipopeptides: modes of action and potential candidates for the treatment of bacterial and fungal infections. Curr Protein Pept Sci 7: 479486, 2006.

30.Al-Benna S, Shai Y, Jacobsen F and Steinstraesser L: Oncolytic activities of host defense peptides. Int J Mol Sci 12: 8027-8051, 2011.

31.Gaspar D, Veiga AS and Castanho MA: From antimicrobial to anticancer peptides. A review. Front Microbiol 4: 294, 2013. 
32. Hirsch T, Jacobsen F, Steinau HU and Steinstraesser L: Host defense peptides and the new line of defence against multiresistant infections. Protein Pept Lett 15: 238-243, 2008.

33. Hirsch T, Metzig M, Niederbichler A, Steinau HU, Eriksson E and Steinstraesser L: Role of host defense peptides of the innate immune response in sepsis. Shock 30: 117-126, 2008.

34. Hoskin DW and Ramamoorthy A: Studies on anticancer activities of antimicrobial peptides. Biochim Biophys Acta 1778: 357-375, 2008.

35.Huang W, Seo J, Willingham SB, et al: Learning from host-defense peptides: cationic, amphipathic peptoids with potent anticancer activity. PLoS One 9: e90397, 2014.

36.Nakatsuji T and Gallo RL: Antimicrobial peptides: old molecules with new ideas. J Invest Dermatol 132: 887-895, 2012.

37.Steinstraesser L, Hauk J, Schubert C, et al: Suppression of soft tissue sarcoma growth by a host defense-like lytic peptide. PLoS One 6: e18321, 2011.

38.Papo N, Seger D, Makovitzki A, et al: Inhibition of tumor growth and elimination of multiple metastases in human prostate and breast xenografts by systemic inoculation of a host defense-like lytic peptide. Cancer Res 66: 5371-5378, 2006.

39.Papo $\mathrm{N}$ and Shai Y: New lytic peptides based on the D,L-amphipathic helix motif preferentially kill tumor cells compared to normal cells. Biochemistry 42: 9346-9354, 2003.

40.Steinstraesser L, Schubert C, Hauk J, et al: Oncolytic designer host defense peptide suppresses growth of human liposarcoma. Int J Cancer 128: 2994-3004, 2011.

41. Hemmerle T, Probst P, Giovannoni L, Green AJ, Meyer T and Neri D: The antibody-based targeted delivery of TNF in combination with doxorubicin eradicates sarcomas in mice and confers protective immunity. Br J Cancer 109: 1206-1213, 2013.

42.Wang S, Ren W, Liu J, et al: TRAIL and doxorubicin combination induces proapoptotic and antiangiogenic effects in soft tissue sarcoma in vivo. Clin Cancer Res 16: 2591-2604, 2010.

43.Leung LK and Wang TT: Differential effects of chemotherapeutic agents on the Bcl-2/Bax apoptosis pathway in human breast cancer cell line MCF-7. Breast Cancer Res Treat 55: 73-83, 1999.

44.Riedl S, Zweytick D and Lohner K: Membrane-active host defense peptides-challenges and perspectives for the development of novel anticancer drugs. Chem Phys Lipids 164: 766-781, 2011.

45.Dings RP, Yokoyama Y, Ramakrishnan S, Griffioen AW and Mayo KH: The designed angiostatic peptide anginex synergistically improves chemotherapy and antiangiogenesis therapy with angiostatin. Cancer Res 63: 382-385, 2003. 
46.Amornsupak K, Insawang T, Thuwajit P, P OC, Eccles SA and Thuwajit C: Cancer-associated fibroblasts induce high mobility group box 1 and contribute to resistance to doxorubicin in breast cancer cells. BMC Cancer 14: 955, 2014.

47.Baguley BC: Multiple drug resistance mechanisms in cancer. Mol Biotechnol 46: 308-316, 2010.

48.Hoffmann J, Schmidt-Peter P, Hansch W, et al: Anticancer drug sensitivity and expression of multidrug resistance markers in early passage human sarcomas. Clin Cancer Res 5: 2198-2204, 1999.

49. Held-Kuznetsov V, Rotem S, Assaraf YG and Mor A: Host-defense peptide mimicry for novel antitumor agents. FASEB J 23: 4299-4307, 2009.

\section{Figures}
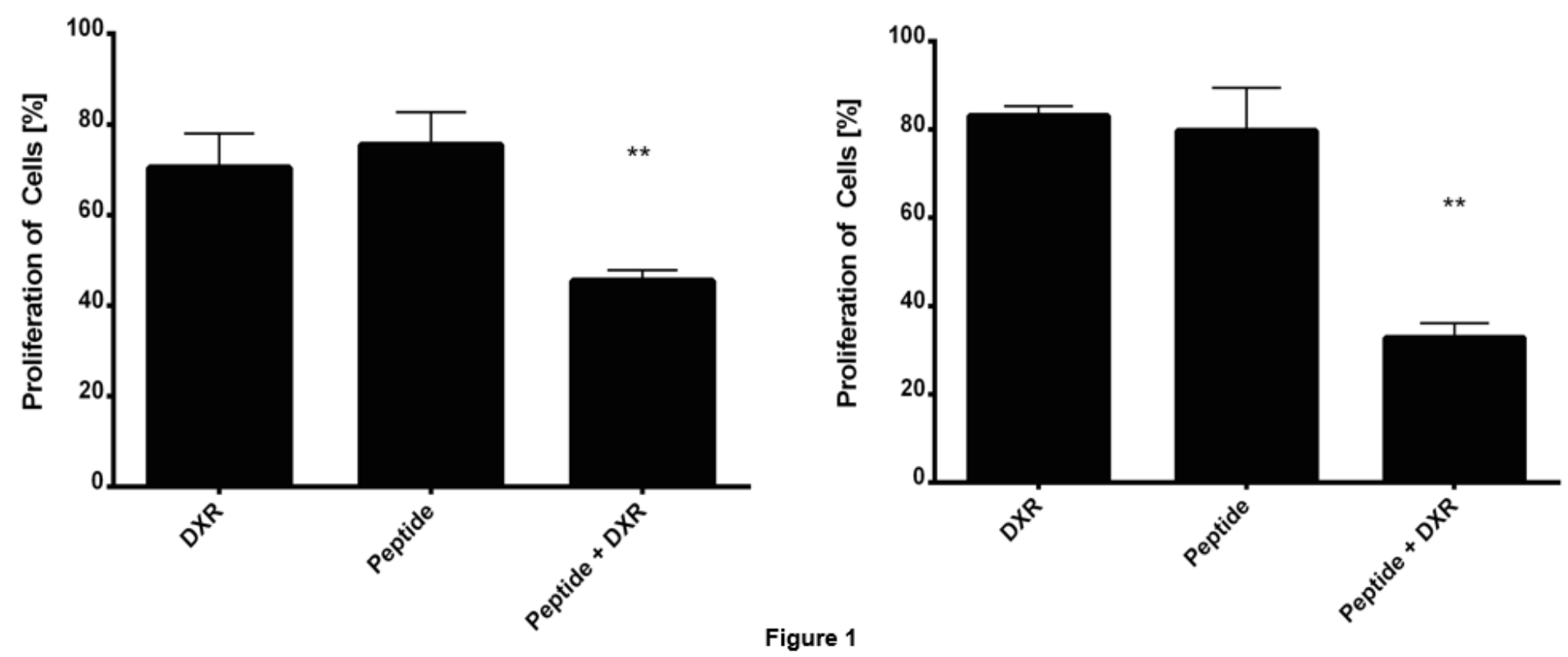

Figure 1

\section{Figure 1}

Cytotoxicity. The combination of both agents revealed an additive effect for the Synovialsarcoma (SW982) cell line (Fig.1a). The antiproliferative efficacy of the single agents with $30 \%$ for Doxorubicin and $25 \%$ for [D]-K3H3L9 led to an addition amount of $55 \%$ under the combined application. The BFS-1 cells showed a synergistic effect underlining the potential of both substances (Fig.1b). A $17 \%$ decreased cell proliferation for Doxorubicin (30 ng) and a $20 \%$ decreased cell proliferation for the peptide $(15 \square \mathrm{g})$ after single incubation, resulted in a $77 \%$ synergistic inhibition. The BrdU assay displayed a highly significant $(p<0.01)$ antiproliferative effect of the combined use of the peptide and Doxorubicin toward both cell lines. 

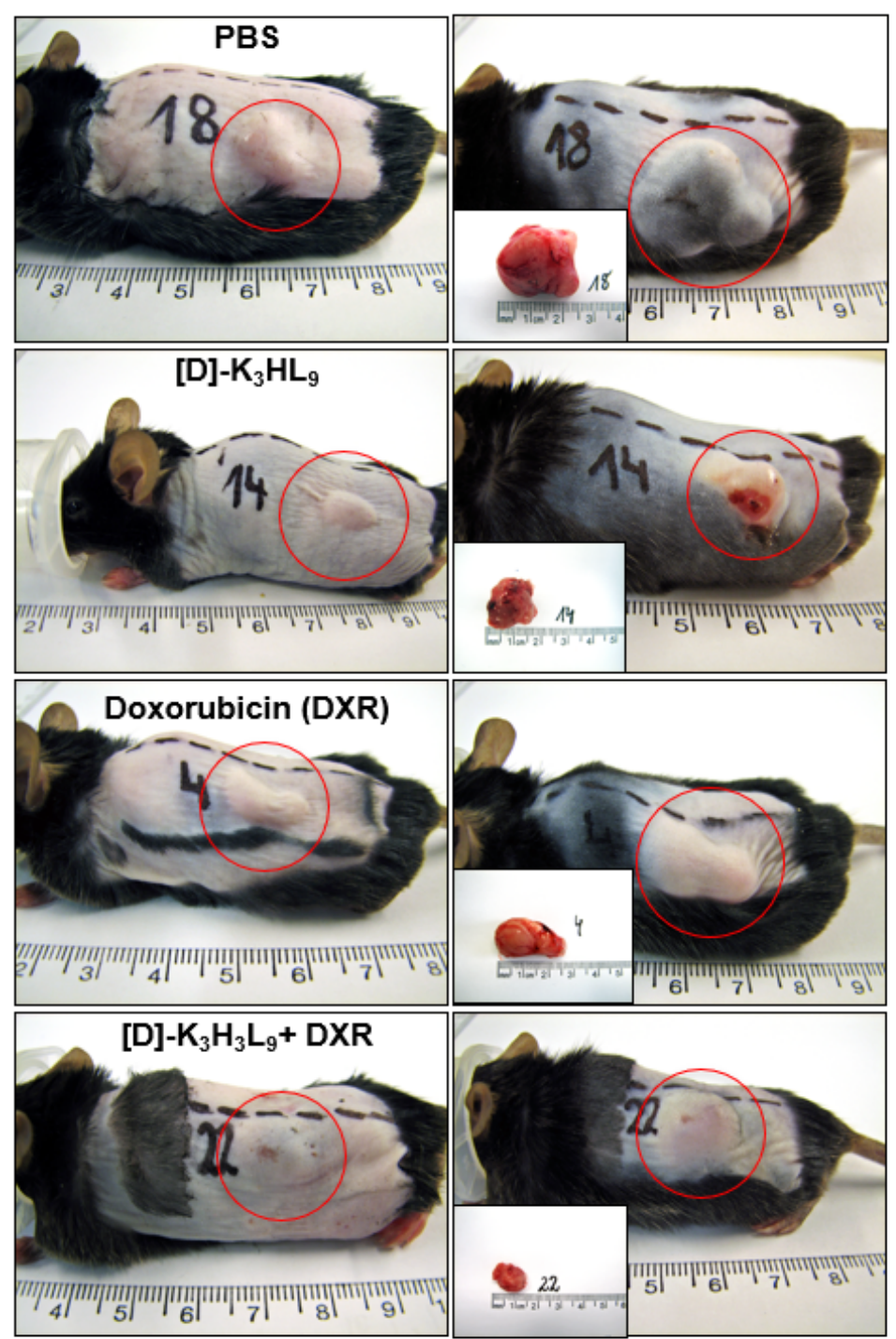

Initiation

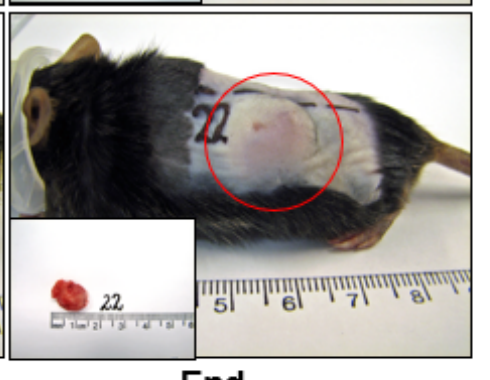

End
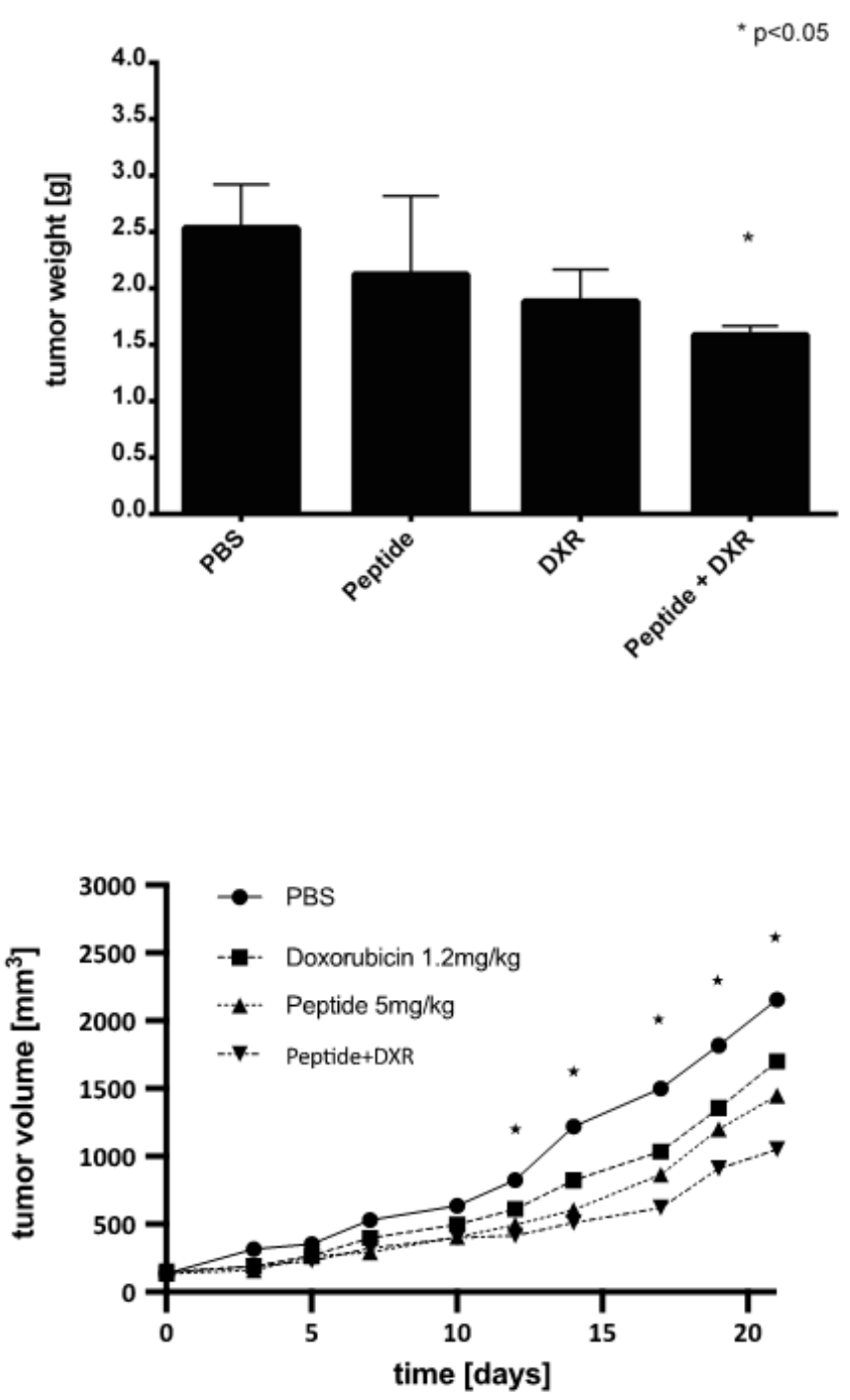

Figure 2

\section{Figure 2}

Tumor weight and Tumor volume over time. Immunocompetent mouse model (C57/BL6 mice) to study the efficacy of single agent therapy with the Peptide [D]-K3H3L9, Doxorubicin and a combination treatment. When the tumors engrafted and reached the average volume of $130 \mathrm{~mm}$, the treatment began on day 0 and ended on day 19 . The peptide was administered in a dose of $5 \mathrm{mg} / \mathrm{kg} \mathrm{BW}$, Doxorubicin in a dose of $1.2 \mathrm{mg} / \mathrm{kg} \mathrm{BW}$. After finishing the therapy, the tumors were removed on day 21 . Volume: The combination therapy revealed a significant reduction of the tumor volume $(p<0.05)$. Compared to the control group, injected with PBS, a $49.05 \%$ reduction of the tumor growth, a $24.04 \%$ reduction of the tumor end volume compared to the peptide and a $35.39 \%$ decreased tumor volume compared to Doxorubicin was reached. The completely dissected tumors of different therapy groups were shown after preparation. All tumors were measured, weighed and documented by photography on the last day of the experiment. Weight: Combined therapy inhibited both the tumor growth and the tumor weight significantly $(p<0.05)$. The tumor weight statistic confirms former results of the tumor volume. The tumor weight was 
significantly reduced under combined therapy with the oncolytic peptide and Doxorubicin $(p<0.05)$. The average reduction was with $1.56 \mathrm{~g}$ about $38.58 \%$ under the weight in the control group with about $2.54 \mathrm{~g}$.

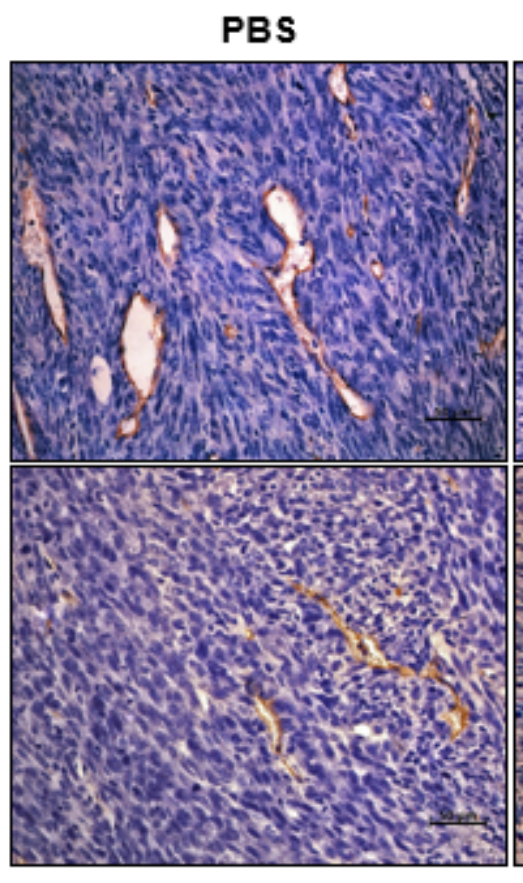

Doxorubicin

\section{Peptide}

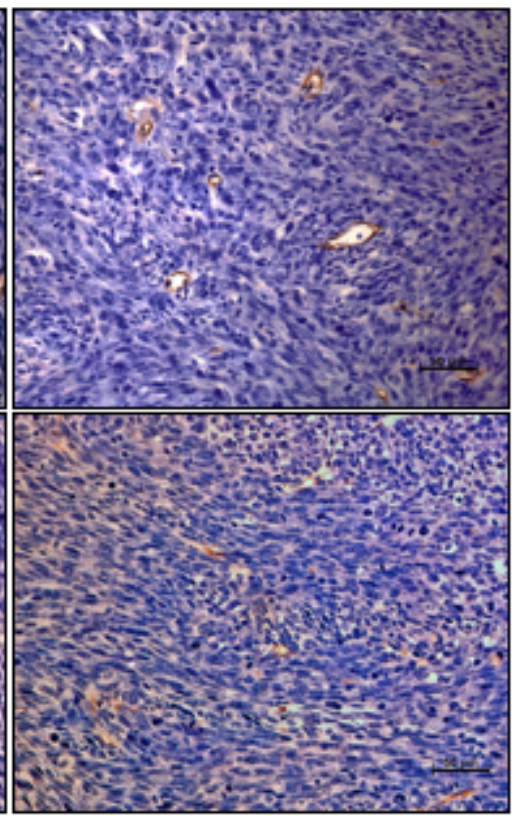

Peptide+Doxorubicin

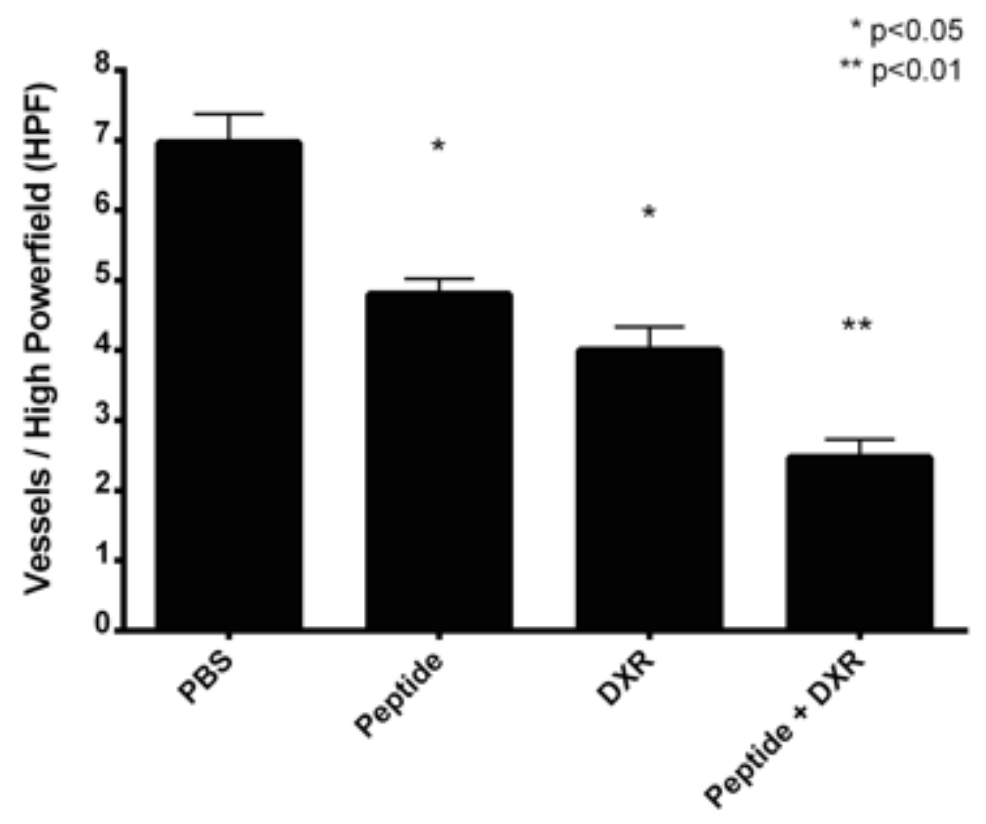

Figure 3

\section{Figure 3}

Anti CD31-immunostaining. Comparison of the vessels' density in the murine fibrosarcoma model underlying the different therapy approaches shows the highly significant $(64.66 \%)$ reduction of the vessels' density after therapy with the HDP and Doxorubicin $(p<0.01)$ using CD31 immunostaining. 
Comparison of vessels' density between different therapeutic regimens in murine fibrosarcoma. The combination therapy with the oncolytic peptide and Doxorubicin leads to a highly significant reduction $(64.66 \%)$ of vessels' density in non-necrotic areas $(p<0.01)$.
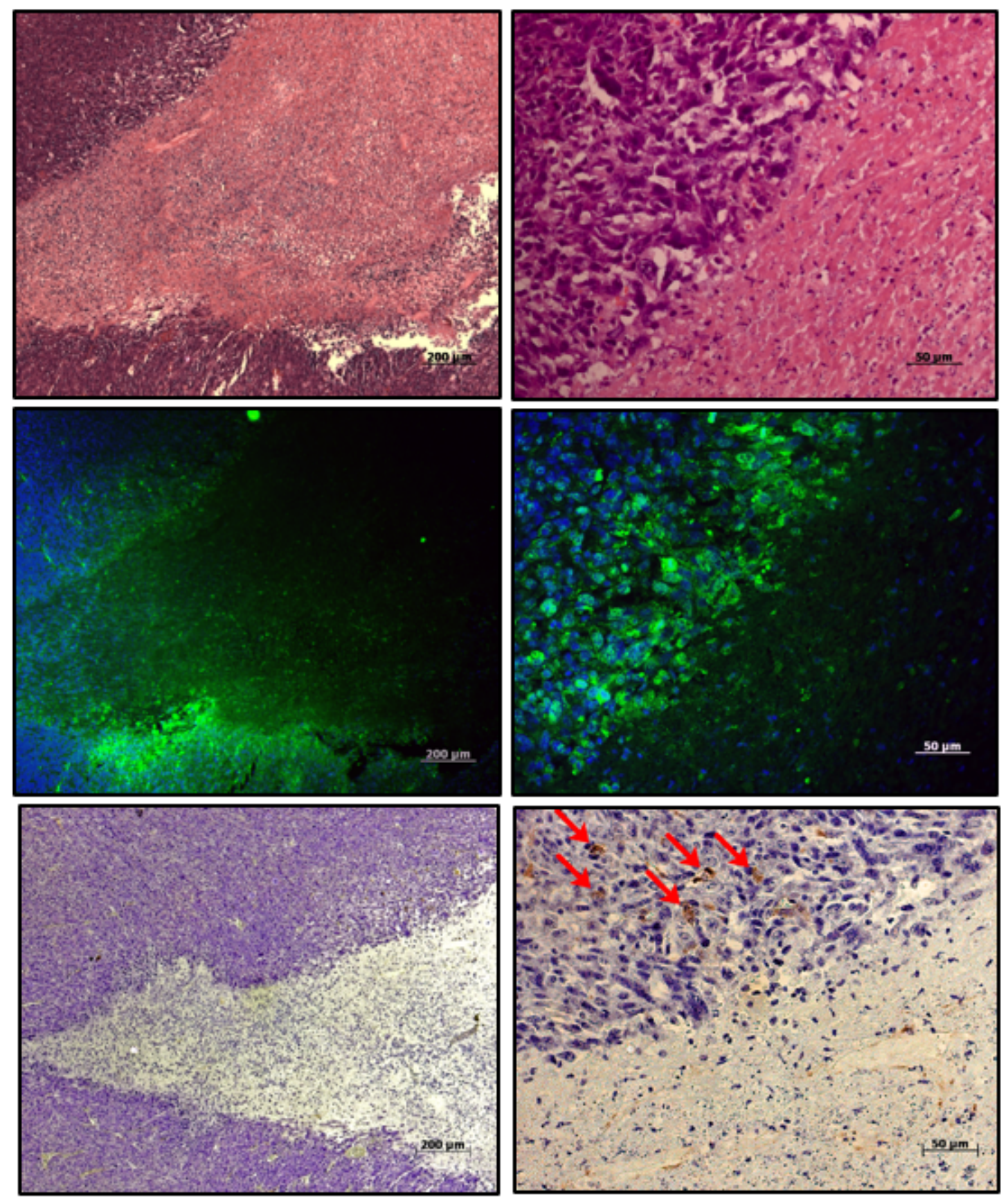

Figure 4

\section{Figure 4}

Injection zone after combination therapy with [D]-K3H3L9 and Doxorubicin. H\&E staining of the dissected fibrosarcomas with focus on the local effect of the oncolytic peptide and Doxorubicin (upper line). Ki-67 immunostaining (middle line) of the same area reveals the necrotic areas of the H\&E stained sections 
and indicates the reduced number of proliferating Ki-67 positive cells (green). The CD31 immunostaining (lower line) shows some isolated endothelia (brown, red marks) but no capillary network. (A: white/black bar $=200 \mu \mathrm{m}, \mathrm{B}:$ white/black bar $=50 \mu \mathrm{m})$

\section{PBS}
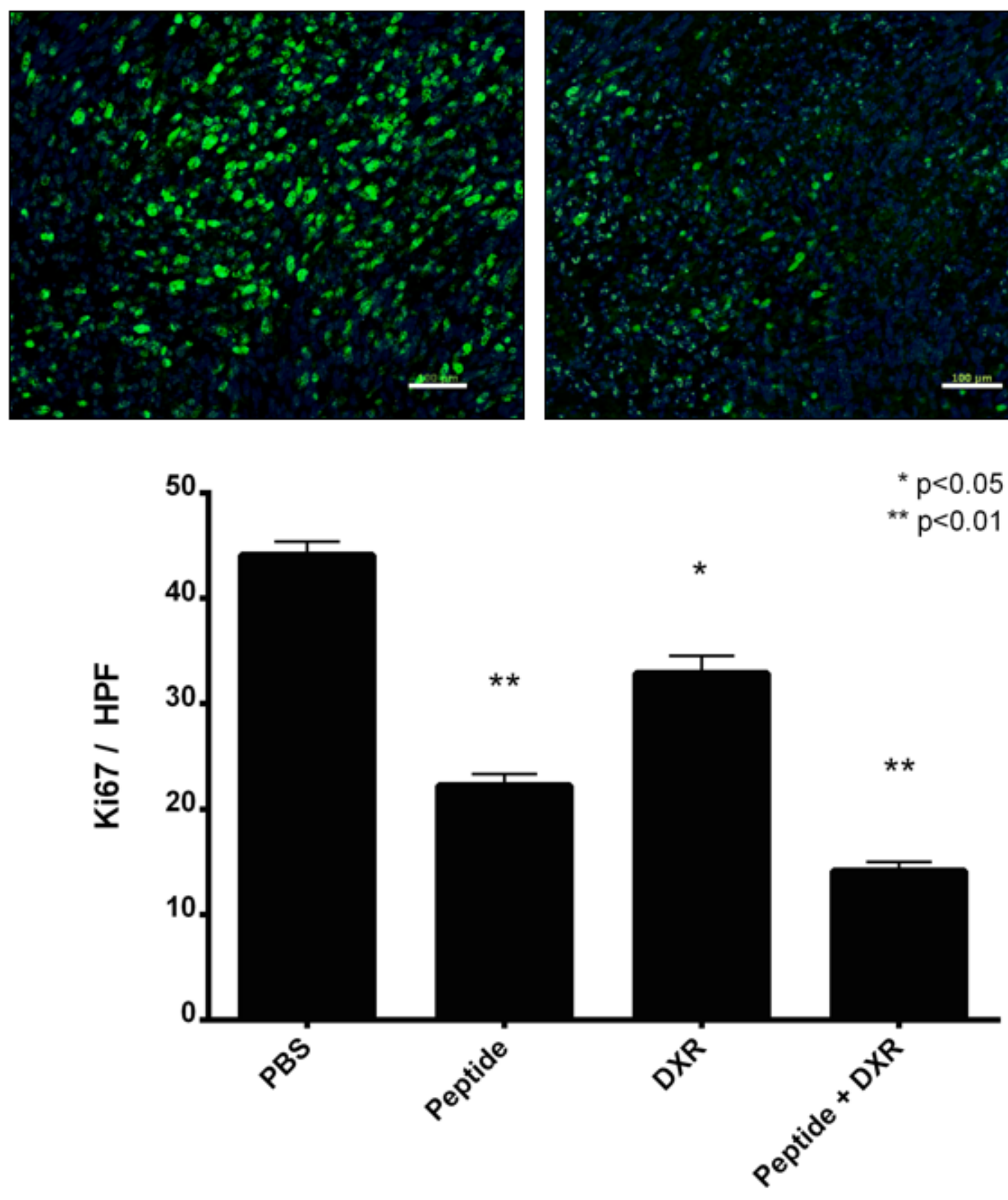

Peptide+Doxorubicin

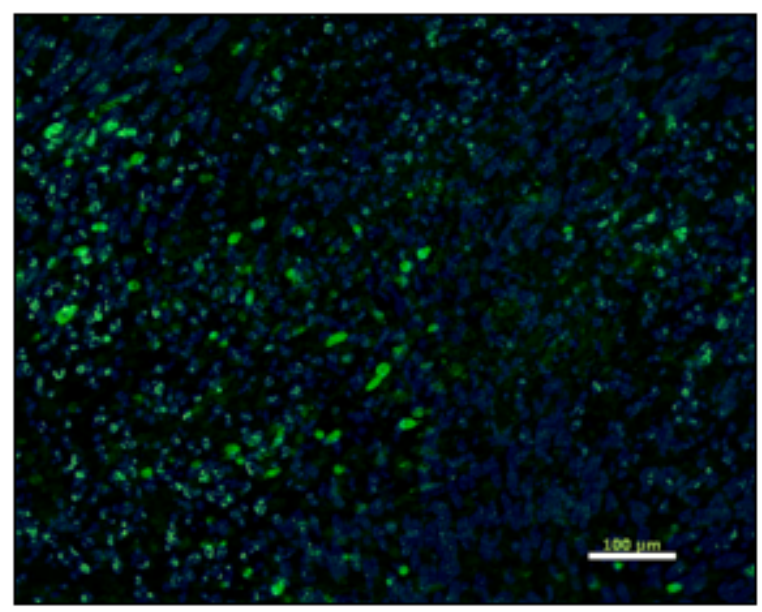

$$
{ }^{*} p<0.05
$$


positive cells was $67.93 \%$ below the control group with an average of 44.06 cells/HPF. After anti-Ki-67staining (core of cells are blue and proliferating cells are green) the significant reduction of the number of proliferating cells, which were treated with both agents, the peptide and DXR, is shown. The number of Ki67 positive cells was $67.93 \%$ lower than in the control group (scale $=100 \mu \mathrm{m}$ ).

\section{Supplementary Files}

This is a list of supplementary files associated with this preprint. Click to download.

- ARRIVEGuidelinesChecklist.pdf 